\title{
Ion-Imprinted Polymer-Based Receptors for Sensitive and Selective Detection of Mercury Ions in Aqueous Environment
}

\author{
Maimoona Yasinzai, ${ }^{1}$ Ghulam Mustafa $\left(\mathbb{D},{ }^{1,2,3}\right.$ Nazia Asghar, $^{1}$ Ikram Ullah, ${ }^{1}$ \\ Muhammad Zahid $\left(\mathbb{D},{ }^{4}\right.$ Peter A. Lieberzeit, ${ }^{3}$ Dongxue Han, ${ }^{2}$ and Usman Latif $\mathbb{D}^{5}$ \\ ${ }^{1}$ Sulaiman Bin Abdullah Aba Al-Khail-Centre for Interdisciplinary Research in Basic Sciences, Faculty of Basic and Applied Sciences, \\ International Islamic University, H-10, Islamabad, Pakistan \\ ${ }^{2}$ Engineering Laboratory for Modern Analytical Techniques, Changchun Institute of Applied Chemistry, Chinese Academy of Science, \\ Ren Min St. 5625, Changchun 130022, China \\ ${ }^{3}$ Department of Physical Chemistry, University of Vienna, Waehringer Strasse 38, 1090 Vienna, Austria \\ ${ }^{4}$ Department of Chemistry, University of Agriculture, Faisalabad, Pakistan \\ ${ }^{5}$ Interdisciplinary Research Centre in Biomedical Materials (IRCBM), COMSATS Institute of Information Technology (CIIT), \\ Lahore 54000, Pakistan
}

Correspondence should be addressed to Ghulam Mustafa; gmustafa@iiu.edu.pk and Usman Latif; usmanlatif@ciitlahore.edu.pk Received 6 October 2017; Revised 25 January 2018; Accepted 5 February 2018; Published 25 March 2018

Academic Editor: Sang Sub Kim

Copyright (c) 2018 Maimoona Yasinzai et al. This is an open access article distributed under the Creative Commons Attribution License, which permits unrestricted use, distribution, and reproduction in any medium, provided the original work is properly cited.

\begin{abstract}
Interdigital electrodes (IDE) coated with ion-imprinted polymers (IIP) as recognition materials have been tested for screening and ion quantification. For screening of receptors, three polymer systems based on styrene (Sty), N-vinylpyrrolidone (NVP), and Styco-NVP were examined to identify an efficient recognition system for mercury ions in an aqueous environment. Results showed that all these polymeric systems can detect analyte even in very low concentration, that is, $10 \mathrm{ppm}$. Ion-imprinted polystyrene system proved to be an ideal receptor for detecting mercury ions in solution with a detection limit of 2 ppm. The sensitivity of ion-imprinted copolymeric system was further enhanced by making its composite with graphene oxide, and estimated detection limit of composite system was around 1 ppm. Ion- imprinted Sty-co-NVP graphene composite-based sensor system exhibits 2 to 5 times higher sensor response towards templated analyte in comparison to other polymer-based sensor systems. Moreover, the composite-based sensor shows very low or negligible response to competing metal ions with similar or different oxidation states such as $\mathrm{Zn}, \mathrm{Mg}, \mathrm{Na}$, and As metal ions.
\end{abstract}

\section{Introduction}

Heavy metals are widely distributed pollutants in aqueous environment, and these are highly toxic to humans and animals even at trace levels [1]. Mercury (II), among other heavy metals, becomes more toxic in aqueous solution when it transforms [2] biologically or chemically to its organic form as methyl mercury, due to its bioaccumulation in living bodies $[3,4]$. Mercury is one of the most hazardous elements for human health because of its relative solubility in water and its tendency to accumulate in human body tissues [5] and causes weakness, neurological damage, and chromosomal mutation $[6,7]$. Therefore, its detection and quantification in water are of substantial importance. Numerous analytical methods and techniques, such as cold vapor atomic absorption spectrometry, atomic fluorescence spectrometry, and inductively coupled plasma mass spectrometry, have been intensively developed for its quantification [8-10]. These techniques are expensive and require trained personnel, and certain complicated processes are involved prior to final analysis. Therefore, development of cost-effective, simple, and robust tools for the detection of heavy metals has attracted considerable interest of analytical chemists which leads to the fabrication of sensors. Limited numbers of reports are available in this field [11-14], and these sensors bear complications and limitations regarding sensitivity, selectivity, and detection of 
ultra-low concentration of mercury ions (e.g., ppt level) in environmental and food samples [15]. Molecular imprinting offers a straight forward and targeted method for producing such polymeric artificial receptors which contains analytespecific molecular recognition properties [16-18]. The general principle of molecular imprinting is based on procedures (as shown in Figure 1) where functional monomer and crosslinkers are polymerized in the presence of a target analyte (the imprinting molecule), which acts as a template. The polymerization process can be performed by reversible covalent and noncovalent interactions between monomers and imprinting molecules.

The imprinting of smaller ionic molecules like metal ions [19] is a tedious task especially from selectivity point of view. In this manuscript, we designed ion-imprinted polymers for $\mathrm{Hg}$ determination in water with remarkable selectivity by using interdigital electrodes (IDEs) as transducer. Furthermore, the sensitivity and selectivity parameters were optimized by using a MIPs/functionalized graphene composite as receptors.

\section{Materials and Methods}

2.1. Chemicals and Reagents. Mercuric iodide $\left(\mathrm{HgI}_{2}\right)$, styrene (Sty), N-vinyl pyrrolidone (NVP), ethylene glycol dimethacrylate (EGDMA), azobisisobutyronitrile (AIBN), graphene oxide $(\mathrm{GO})$, sodium chloride $(\mathrm{NaCl})$, magnesium chloride $\left(\mathrm{MgCl}_{2}\right)$, Arsenic chloride $\left(\mathrm{AsCl}_{3}\right)$, and zinc chloride $\left(\mathrm{ZnCl}_{2}\right)$ were purchased from Sigma-Aldrich and Merck.

\subsection{Synthesis of Ion-Imprinted Polymers and Composites}

2.2.1. Ion-Imprinted Polystyrene. $\mathrm{Hg}$ (II)-imprinted polystyrene was synthesized by using styrene as monomer, EGDMA as crosslinker, and AIBN as initiator while using $\mathrm{Hgl}_{2}$ as template. At first, $\mathrm{Hg}^{2+}$ solution was prepared by dissolving $0.002 \mathrm{~g}$ of $\mathrm{Hgl}_{2}$ in $200 \mu \mathrm{L}$ of THF. Then, $30 \mu \mathrm{l}$ of styrene, $70 \mathrm{mg}$ of EGDMA, and $5 \mathrm{mg}$ of $\mathrm{AIBN}$ were added in $\mathrm{HgI}_{2}$ solution. The resultant mixture was stirred vigorously and polymerized by heating at $60^{\circ} \mathrm{C}$ until its gelation point.

2.2.2. Ion-Imprinted Poly(Vinylpyrrolidone). $\mathrm{Hg}$ (II)-imprinted poly(vinylpyrrolidone) was synthesized by following the above-mentioned procedure using NVP as monomer instead of styrene while keeping all other parameters constant.

2.2.3. Ion-Imprinted Poly(Styrene-Co-Vinyl Pyrrolidone). $\mathrm{Hg}$ (II)-imprinted poly(styrene-co-vinyl pyrrolidone) was synthesized by following the abovementioned procedure using both styrene and NVP as monomers in $(2: 1)$ while keeping all other parameters constant.

2.2.4. Ion-Imprinted Copolymer-Graphene Oxide Composite. $\mathrm{Hg}$ (II)-imprinted copolymer-graphene oxide composite was prepared by adding $30 \mu \mathrm{L}$ of styrene, $10 \mu \mathrm{L}$ of NVP, $70 \mathrm{mg}$ of EGDMA, and $5 \mathrm{mg}$ of AIBN and graphene oxide in $200 \mu \mathrm{L}$ solution of $\mathrm{HgI}_{2}(0.002 \mathrm{~g})$. The resultant mixture was stirred vigorously and polymerized by heating at $60^{\circ} \mathrm{C}$ until its gelation point.
2.2.5. Nonimprinted Polymer. Nonimprinted polymer (NIP) was prepared by following the above-mentioned procedure but without adding any template $\left(\mathrm{HgI}_{2}\right)$.

2.2.6. Immobilization of Receptors onto Transducer and Measurements. Thin films (80-100 nm thickness) of receptors were prepared onto the interdigital electrodes (IDEs) by spin coating $10 \mu \mathrm{L}$ of solution at $2500 \mathrm{rpm}$. Afterward, thin films were dried overnight at $80^{\circ} \mathrm{C}$ and then washed with distilled water to remove the template. LCR meter (IET 7600 Plus precision LCR meter) was used to measure various concentrations of analyte and competing ions at $20 \mathrm{~Hz}$ and $1000 \mathrm{~Hz}$. The synthetic procedure and measuring setup are shown in Figure 2.

\section{Results and Discussions}

Ion-imprinted polymer (IIP), coated on transducer (IDE) surface, contains recognition cavities to selectively bind mercuric ions. The incorporation of templated ions, from sample solution, into these cavities results in changing electrical properties of IIP-coated layer. Conductivity of IIP layer increases with incorporation of metal ions into recognition sites. Thus, conductance of IIP layer is directly proportional to metal ion concentration incorporated into the cavities. NVP-based $\mathrm{Hg}^{2+}$-imprinted receptor system was synthesized by using EGDMA as crosslinker. Polymer system interacts with $\mathrm{Hg}^{2+}$ ions via electron-enriched entities present in their structure. Sensitivity of polymer systems was analysed through exposing them to various concentrations of templated ion ranging from $90-10$ ppm as shown in Figure 3. The conductance of IIP layer at $90 \mathrm{ppm}$ was $69 \mu \mathrm{S}$ which reduces to $56,50,46$, and $35 \mu \mathrm{S}$ at $70,50,30$, and $10 \mathrm{ppm}$, respectively. The sensor system shows a quite linear response: the conductivity decreases with decreasing concentration of analyte. Nonimprinted polymer expressed almost very negligible response while exposing to various analyte concentrations. The estimated value of LOD, measured from calibration curve, is around $4 \mathrm{ppm}$.

The sensitivity of styrene-based IIP was investigated while exposing to various concentrations of templated ions. The metal ion undergoes coordination or chelation with electron-rich entities present in polymer material. The sensor showed a response of $103 \mu \mathrm{S}$ at $90 \mathrm{ppm}$ of analyte concentration. By lowering analyte concentration from 90 to $10 \mathrm{ppm}$, the sensor response decreased to $54 \mathrm{~Hz}$. At 70, 50, and $30 \mathrm{ppm}$ of analyte concentration, the conductivity of material shifts from 92, 78, to $67 \mu \mathrm{S}$, respectively. The response of NIP is almost negligible as compared to ion-imprinted-based sensor system as shown in Figure 4. The lowest detection limit of styrene-based polymer was around $2 \mathrm{ppm}$, estimated from calibration curve.

Styrene is a hydrophobic monomer with no special functionality. The role it may play in polymer formation is to form an imprint of the $\mathrm{Hg}^{2+}$ ion where it could specifically fix and coordinate with the crosslinking agent, that is, EGDMA. It thus induces geometric fit cavities in IIP, which enable polymer matrix for selective incorporation of templated ions. It is notable from the above results that 


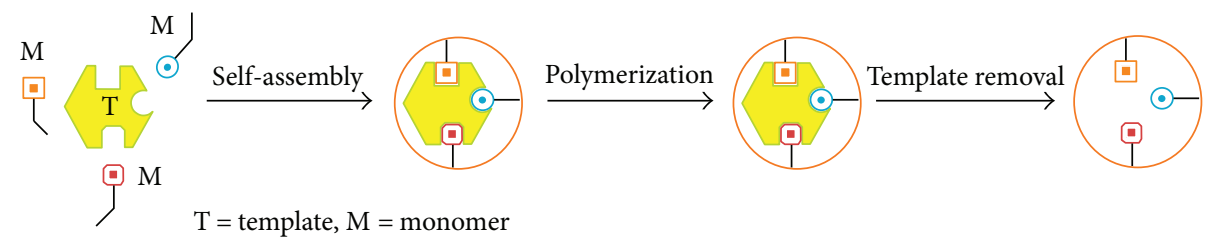

FIGURE 1: Molecular imprinting strategy.

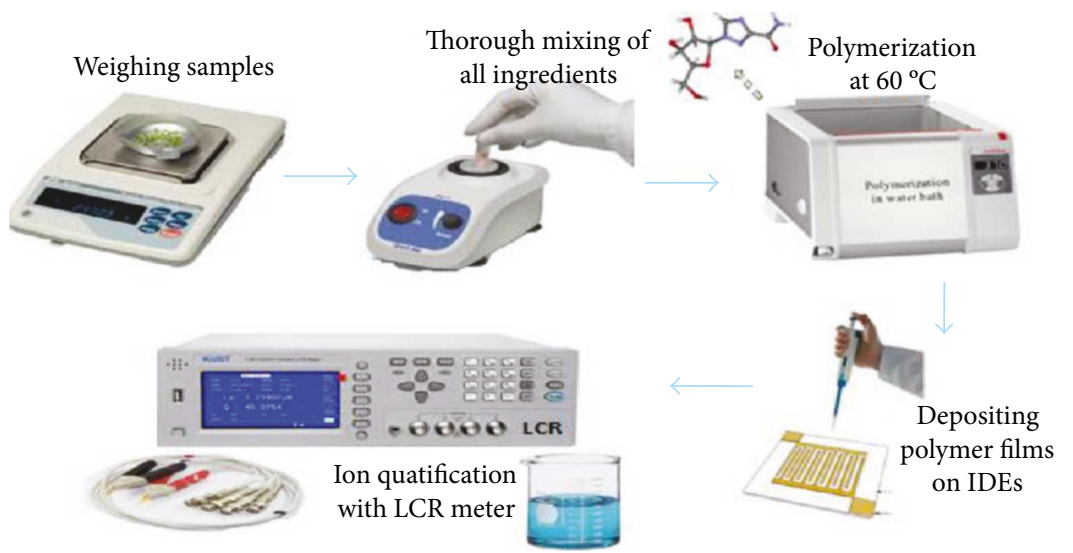

FigURE 2: Receptor synthesis and sensor setup.

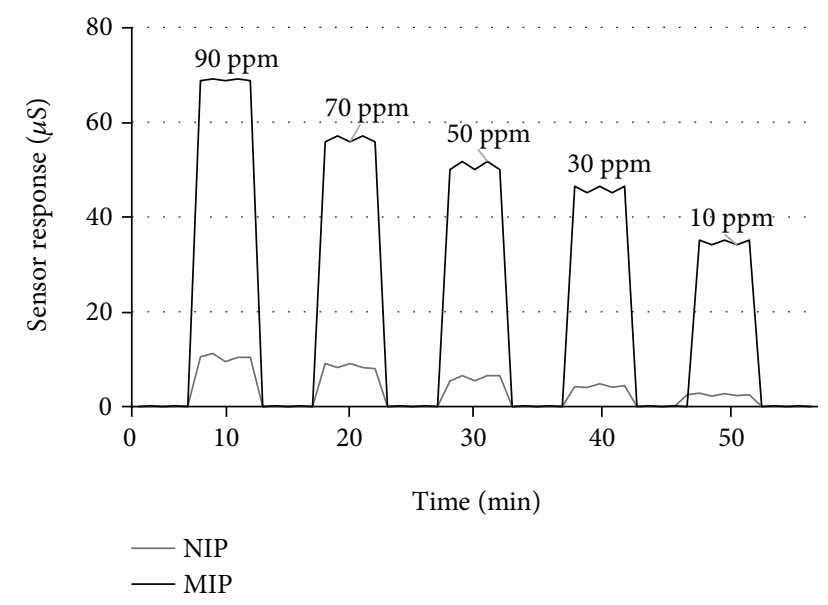

FIGURE 3: Sensitivity response of NVP-based $\mathrm{Hg}^{2+}$-imprinted and nonimprinted polymers towards different concentrations of mercury solutions.

polystyrene-based polymer produces higher sensor effect than NVP system due to its aromaticity and functionality.

Ion-imprinted copolymer system based on Sty and NVP was also synthesized (radical copolymerization) to analyse its interaction towards templated analyte. The amide group of NVP has a high binding affinity for several molecules due to its polar nature and has been copolymerized with a variety of monomers [20-24]. N-vinylpyrrolidone can copolymerize with styrene and yields maximum sensor signal [25].

Sensitivity of copolymer system was investigated through exposing it to different analyte concentrations as shown in Figure 5. The sensor response based on copolymer system towards $90 \mathrm{ppm}$ analyte concentration was $96 \mu \mathrm{S}$ which was decreased to $81,70,56$, and $38 \mu \mathrm{S}$ at $70,50,30$, and $10 \mathrm{ppm}$, respectively. The graph depicts a linear- and concentrationdependent sensor response. The estimated lowest detection limit of ion-imprinted copolymer sensor system is around $2 \mathrm{ppm}$.

To achieve higher sensitivity and excellent performances, the structure of imprinted material was optimized in such a way that recognition sites should be situated at the surface or in the proximity of material surface. Graphene, with unique mechanical properties and extremely large area, is an excellent candidate as a supporting material for preparing imprinted materials. The prepared IIPs would be in possession of large surface area in case the polymerization occurs at the surface of graphene sheets (GS). The binding sites in the outer layer of IIP composite provide complete removal of templates, improve accessibility to target species, and reduce its binding time. Graphene oxide is a typical pseudo two-dimensional oxygen containing solid in bulk form, which possesses functional groups including hydroxyl, epoxide, and carboxyl [26-28]. Graphene oxide, covalently and noncovalently, is known to attach both small molecules and polymers to its reactive oxygen functionalities [29]. The sensitivity of IIP-graphene composite system substantially enhanced towards its templated analyte attributed to the excellent electric and mechanical properties of graphene oxide as shown in Figure 6. At $90 \mathrm{ppm}$ of analyte concentration, there is a drastic increase in the conductance which is $295 \mu \mathrm{S}$, in comparison to Sty, NVP, or Sty-co-NVP polymerbased sensor systems. The graph shows a linear response of $272,246,201$, and $167 \mu \mathrm{S}$ while exposing to $70,50,30$, and $10 \mathrm{ppm}$ analyte concentration, respectively. 


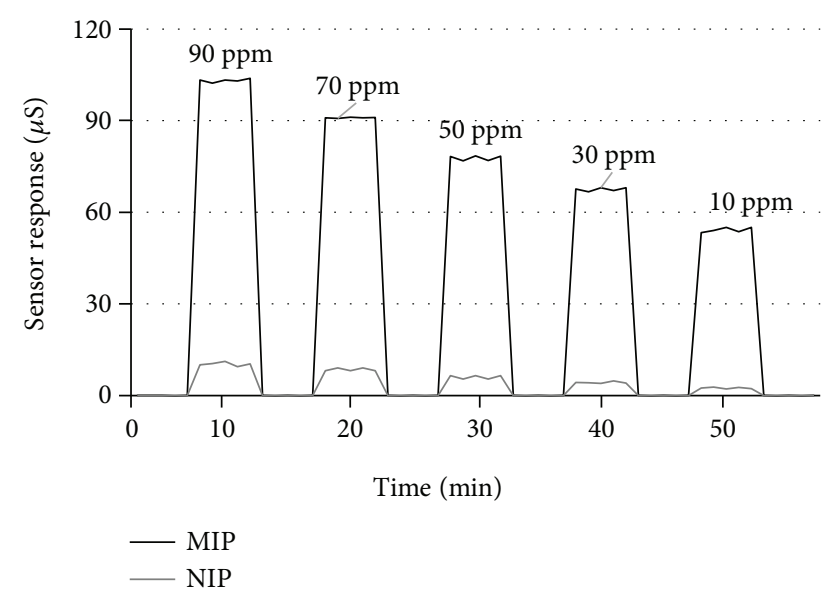

FIGURE 4: Sensitivity response of styrene-based $\mathrm{Hg}^{2+}$-imprinted and nonimprinted sensors towards different concentrations of mercury solutions.

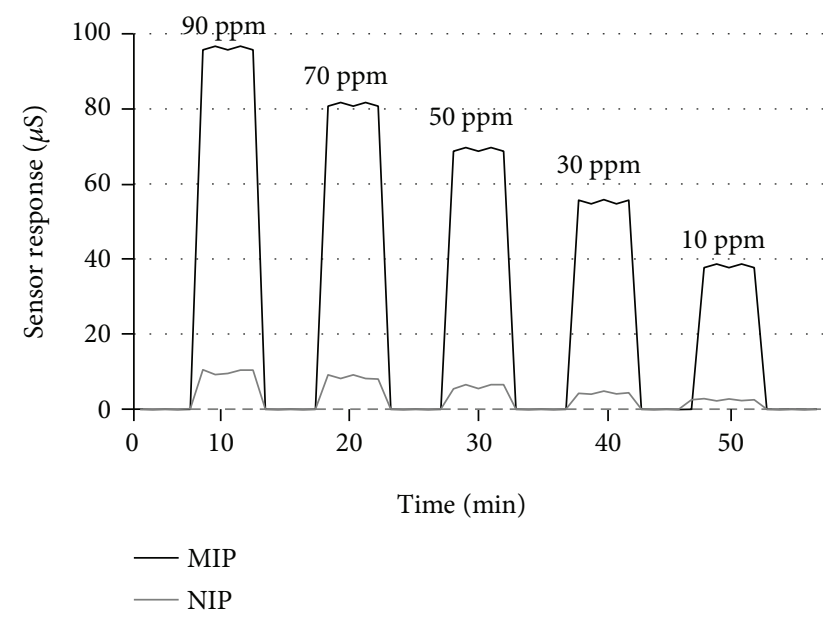

FIGURE 5: Sensitivity response of $\mathrm{Hg}^{2+}$-imprinted and nonimprinted Sty-NVP copolymer systems.

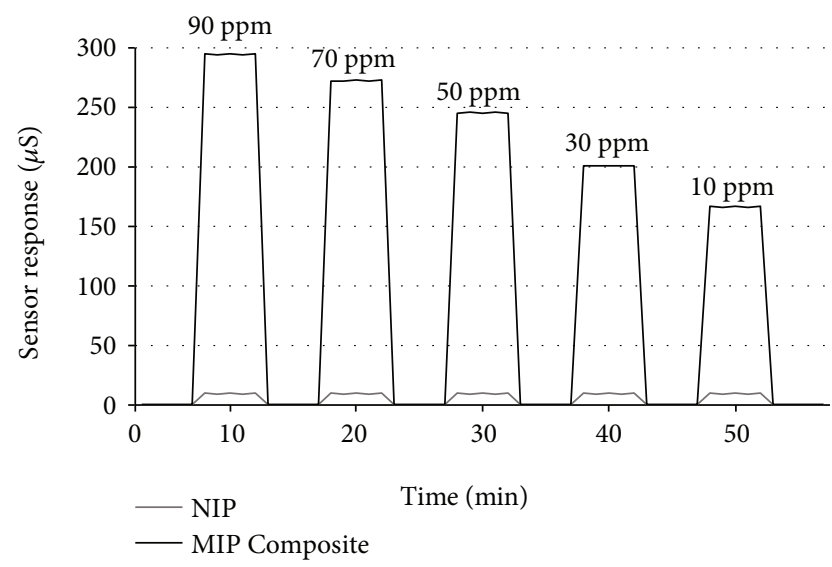

FIGURE 6: Sensitivity response of $\mathrm{Hg}^{2+}$-imprinted Sty-co-NVP graphene composite and nonimprinted composite sensor while exposing to various concentrations of analyte ranging from $10-90$ ppm.

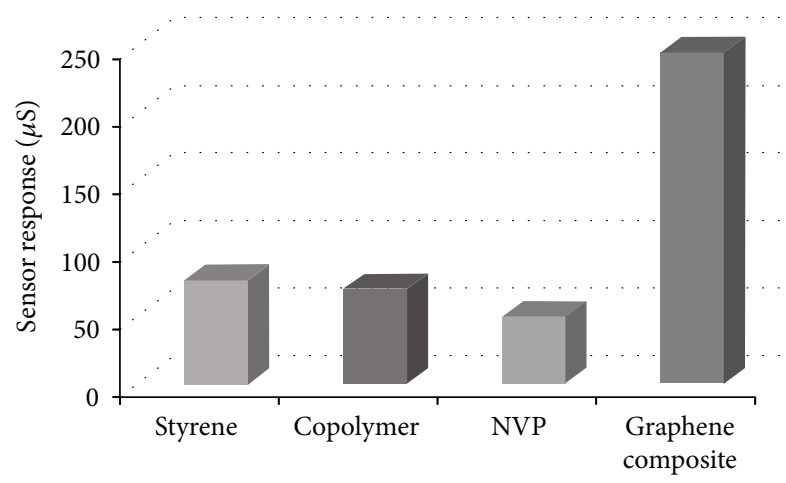

FIgURE 7: Comparison of four different $\mathrm{Hg}^{2+}$-imprinted polymerbased receptors at concentrations $50 \mathrm{ppm}$ of templated ion solution.

The ratio of monomer to crosslinker was 30:70. High crosslinker ratio gives three dimensional spaces that are selective for $\mathrm{Hg}^{2+}$ ions whereas lower crosslinker ratio in a polymer composition will cause imprinting sites to collapse. The composite-based sensor system is highly sensitive to templated analyte and is the only material responding to concentrations down to $0.9 \mathrm{ppm}$ (estimated by calibration curve) in comparison to simple ion-imprinted polymer-based sensor, as shown in Figure 6. One of the most important reactions of graphene oxide is its reduction. Electron-rich hydroxyl group and oxygen functionalities on graphene oxide surface interact with electron-deficient mercuric ions present in sample solution.

All ion-imprinted polymeric- and composite-based sensor system exhibits a linear response towards templated analyte, which enhances with an increase in analyte concentrations. All polymer-based systems show sensor response in a similar range; however, an almost 3-fold increase in sensitivity was achieved by making template-specific recognition sites on graphene sheets as shown in Figure 7. This increase in conductivity of graphene sheets is due to its high surface area in comparison to all other polymer thin films, and secondly, it contributes to sensitivity because of its oxygen and mercuric ion interaction. N-vinylpyrrolidone (NVP) shows good biocompatibility due to their hydrophilic nature and low cytotoxicity [30-37]. Electron-deficient $\mathrm{Hg}^{2+}$ ions interact with electron-rich moieties of NVP/ EGDMA. Aqueous environment affects the performance of NVP-based receptors because of their hydrophilic nature. The quality of NVP-based receptors was further improved by copolymerizing it with hydrophobic monomer (styrene).

Sensitivity analysis alone is not sufficient to evaluate a sensor system. Thus, it is very necessary to investigate sensor selectivity by exposing it to structurally related analogues. After removing the template molecules by extraction, a molecularly imprinted polymer was analysed against other metal ions typically, such as $\mathrm{Zn}^{2+}, \mathrm{Mg}^{2+}, \mathrm{As}^{3+}$, and $\mathrm{Na}^{+}$. These ions were chosen as competitors to evaluate selectivity performance for $\mathrm{Hg}^{2+}$-imprinted polymeric and composite systems.

It is evident from Figure 8 that $\mathrm{Hg}^{2+}$-imprinted polymers and composites comprise binding sites which are highly 


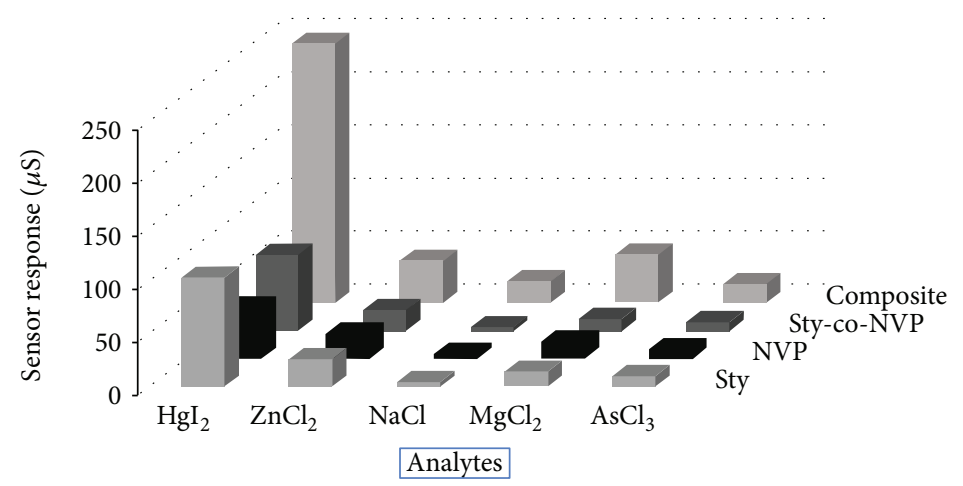

Figure 8: Selectivity of $\mathrm{Hg}^{2+}$-imprinted polymer-based sensor systems against other competing metal ions at $50 \mathrm{ppm}$ concentrations.

selective to templated ion. The monomers and crosslinkers arrange themselves around template ions during polymerization, in such an efficient way, to produce highly selective recognition sites which can accommodate only specific analyte. All these ion-imprinted polymer-based receptors show concentration-dependent linear response which reduces with decrease in analyte concentration. The $\mathrm{Hg}^{2+}$-imprinted Styco-NVP-graphene composite-based sensor shows 2-5-folds higher sensor response to $\mathrm{Hg}^{2+}$ in comparison to other polymer-based systems. Moreover, it remains very less responsive to other metal ions with similar oxidation state as $\mathrm{Hg}^{2+}$, and it further reduces towards metal ions having lower or higher oxidation states.

The fabricated sensor proved to be suitable for heavy metal ion detection in aqueous environment even in the presence of other competing metal ions.

\section{Conclusion}

In this work, $\mathrm{Hg}(\mathrm{II})$-imprinted polymeric- and compositebased sensor systems were fabricated by following molecular imprinting approach. Four different receptors were synthesized based on different polymeric systems such as (i) polystyrene, (ii) poly(vinylpyrrolidone), (iii) Sty-co-NVP polymer, and IIP composite of Sty-co-NVP polymer and graphene sheets. Efficiency of these sensor systems was investigated while exposing to their templated analytes. The sensitivity and selectivity of ion-imprinted polymers and composite were in the following order: composite $>$ Sty $>$ copolymers $>$ NVP. The results indicate that a very sensitive, selective, low-cost, and user-friendly sensor system can be fabricated for any metal by combining molecular imprinting approach and interdigital transducers.

\section{Conflicts of Interest}

The authors declare that there is no conflict of interest regarding the publication of this article.

\section{References}

[1] R. B. Hayes, "The carcinogenicity of metals in humans," Cancer Causes \& Control, vol. 8, no. 3, pp. 371-385, 1997.
[2] B. S. Batlokwa, L. Chimuka, Z. Tshentu, E. Cukrowska, and N. Torto, "An ion-imprinted polymer for the selective extraction of mercury (II) ions in aqueous media," Water SA, vol. 38, no. 2, pp. 255-260, 2012.

[3] C. T. Driscoll, R. P. Mason, H. M. Chan, D. J. Jacob, and N. Pirrone, "Mercury as a global pollutant: sources, pathways, and effects," Environmental Science \& Technology, vol. 47, no. 10, pp. 4967-4983, 2013.

[4] Y. Huang, J. R. Du, Y. Zhang, D. Lawless, and X. Feng, "Removal of mercury (II) from wastewater by polyvinylamineenhanced ultrafiltration," Separation and Purification Technology, vol. 154, pp. 1-10, 2015.

[5] J. G. Wiener, D. P. Krabbenhoft, G. H. Heinz, and A. M. Scheuhammer, "Ecotoxicology of mercury," in Handbook of Ecotoxicology, pp. 409-463, CRC Press, Boca Raton, FL, USA, 2 edition, 2003.

[6] D. K. Singh and S. Mishra, "Synthesis and characterization of $\mathrm{Hg}(\mathrm{II})$-ion-imprinted polymer: kinetic and isotherm studies," Desalination, vol. 257, no. 1-3, pp. 177-183, 2010.

[7] L. Mergola, S. Scorrano, E. Bloise et al., "Novel polymeric sorbents based on imprinted $\mathrm{Hg}$ (II)-diphenylcarbazone complexes for mercury removal from drinking water," Polymer Journal, vol. 48, no. 1, pp. 73-79, 2016.

[8] M. Resano, J. Briceño, and M. Belarra, "Direct determination of $\mathrm{Hg}$ in polymers by solid sampling-graphite furnace atomic absorption spectrometry: a comparison of the performance of line source and continuum source instrumentation," Spectrochimica Acta Part B: Atomic Spectroscopy, vol. 64, no. 6, pp. 520-529, 2009.

[9] K. Leopold, M. Foulkes, and P. J. Worsfold, “Gold-coated silica as a preconcentration phase for the determination of total dissolved mercury in natural waters using atomic fluorescence spectrometry," Analytical Chemistry, vol. 81, no. 9, pp. 34213428, 2009.

[10] R. Ito, M. Kawaguchi, N. Sakui et al., "Stir bar sorptive extraction with in situ derivatization and thermal desorption-gas chromatography-mass spectrometry for trace analysis of methylmercury and mercury(II) in water sample," Talanta, vol. 77, no. 4, pp. 1295-1298, 2009.

[11] X. Xue, F. Wang, and X. Liu, "One-step, room temperature, colorimetric detection of mercury $\left(\mathrm{Hg}^{2+}\right)$ using DNA/nanoparticle conjugates," Journal of the American Chemical Society, vol. 130, no. 11, pp. 3244-3245, 2008.

[12] M. Yuan, Y. Li, J. Li et al., "A colorimetric and fluorometric dual-modal assay for mercury ion by a molecule," Organic Letters, vol. 9, no. 12, pp. 2313-2316, 2007. 
[13] M. Hollenstein, C. Hipolito, C. Lam, D. Dietrich, and D. M. Perrin, "A highly selective DNAzyme sensor for mercuric ions," Angewandte Chemie International Edition, vol. 47, no. 23, pp. 4346-4350, 2008.

[14] D. Li, A. Wieckowska, and I. Willner, "Optical analysis of $\mathrm{Hg}^{2+}$ ions by oligonucleotide-gold-nanoparticle hybrids and DNA-based machines," Angewandte Chemie, vol. 120, no. 21, pp. 3991-3995, 2008.

[15] D. Song, R. Yang, H. Wang et al., "A label-free SERRS-based nanosensor for ultrasensitive detection of mercury ions in drinking water and wastewater effluent," Analytical Methods, vol. 9, no. 1, pp. 154-162, 2017.

[16] W. M. Mullett, E. P. C. Lai, and B. Sellergren, "Determination of nicotine in tobacco by molecularly imprinted solid phase extraction with differential pulsed elution," Analytical Communications, vol. 36, no. 6, pp. 217-220, 1999.

[17] K. Haupt, A. Dzgoev, and K. Mosbach, "Assay system for the herbicide 2,4-dichlorophenoxyacetic acid using a molecularly imprinted polymer as an artificial recognition element," Analytical Chemistry, vol. 70, no. 3, pp. 628-631, 1998.

[18] P. Turkewitsch, B. Wandelt, G. D. Darling, and W. S. Powell, "Fluorescent functional recognition sites through molecular imprinting. A polymer-based fluorescent chemosensor for aqueous cAMP," Analytical Chemistry, vol. 70, no. 10, pp. 2025-2030, 1998.

[19] S. Z. Bajwa, R. Dumler, and P. A. Lieberzeit, "Molecularly imprinted polymers for conductance sensing of $\mathrm{Cu}^{2+}$ in aqueous solutions," Sensors and Actuators B: Chemical, vol. 192, pp. 522-528, 2014.

[20] M. Otagiri, T. Imai, H. Koinuma, and U. Matsumoto, "Spectroscopic study of the interaction of coumarin anticoagulant drugs with polyvinylpyrrolidone," Journal of Pharmaceutical and Biomedical Analysis, vol. 7, no. 8, pp. 929-935, 1989.

[21] R. J. Mumper, J. G. Duguid, K. Anwer, M. K. Barron, H. Nitta, and A. P. Rolland, "Polyvinyl derivatives as novel interactive polymers for controlled gene delivery to muscle," Pharmaceutical Research, vol. 13, no. 5, pp. 701-709, 1996.

[22] B. S. R. Reddy, R. Arshady, and M. H. George, "Copolymerization of $\mathrm{N}$-vinyl-2-pyrrolidone with 2,4,5-trichlorophenyl acrylate and with 2-hydroxyethyl methacrylate: reactivity ratios and molecular weights," European Polymer Journal, vol. 21, no. 6, pp. 511-515, 1985.

[23] S. Morariu and C. Hulubei, "Radical copolymerization of functional N-substituted maleimides with N-vinyl-2-pyrrolidone," High Performance Polymers, vol. 18, no. 2, pp. 185198, 2006.

[24] G. Bauduin, B. Boutevin, M. Belbachir, and R. Meghabar, "Determination of reactivity ratios in radical copolymerization: a comparison of methods for a methacrylate/ $\mathrm{N}$-vinylpyrrolidone system," Macromolecules, vol. 28, no. 6, pp. 1750-1753, 1995.

[25] N. Iqbal, G. Mustafa, and P. A. Lieberzeit, "Mass sensitive multi-sensor platform for receptor screening and quantification purposes," Journal of the Chinese Advanced Materials Society, vol. 1, no. 3, pp. 200-209, 2013.

[26] B. Gao, Q. Niu, and R. Du, "Preparation and recognition performance of cytisine alkaloid-imprinted material prepared using novel surface molecular imprinting technique," Journal of Separation Science, vol. 33, no. 9, pp. 1338$1348,2010$.
[27] S. Stankovich, D. A. Dikin, R. D. Piner et al., "Synthesis of graphene-based nanosheets via chemical reduction of exfoliated graphite oxide," Carbon, vol. 45, no. 7, pp. 1558-1565, 2007.

[28] Y. Mao, Y. Bao, S. Gan, F. Li, and L. Niu, "Electrochemical sensor for dopamine based on a novel graphene-molecular imprinted polymers composite recognition element," Biosensors and Bioelectronics, vol. 28, no. 1, pp. 291-297, 2011.

[29] D. R. Dreyer, S. Park, C. W. Bielawski, and R. S. Ruoff, "The chemistry of graphene oxide," Chemical Society Reviews, vol. 39, no. 1, pp. 228-240, 2010.

[30] D. Radić and L. Gargallo, "Synthesis, reactivity ratios, and solution behavior of vinylpyrrolidone-co-monoalkyl itaconate and vinylpyrrolidone-co-dialkyl itaconate copolymers," Macromolecules, vol. 30, no. 4, pp. 817-825, 1997.

[31] A. A. A. De Queiroz, R. R. Vargas, O. Z. Higa, R. R. Ribeiro, and M. Vítolo, "Lactam-amide graft copolymers as novel support for enzyme immobilization," Journal of Applied Polymer Science, vol. 84, no. 4, pp. 767-777, 2002.

[32] S. K. Bajpai and J. Sonkusley, "Hydrogels for oral drug delivery of peptides: synthesis and characterization," Journal of Applied Polymer Science, vol. 83, no. 8, pp. 1717-1729, 2002.

[33] T. Beitz, J. Köetz, G. Wolf, E. Kleinpeter, and S. E. Friberg, "Poly(N-vinyl-2-pyrrolidone) and 1-octyl-2-pyrrolidinone modified ionic microemulsions," Journal of Colloid and Interface Science, vol. 240, no. 2, pp. 581-589, 2001.

[34] M. Basri, A. Harun, M. Ahmad, C. Razak, and A. Salleh, "Immobilization of lipase on poly ( $\mathrm{N}$-vinyl-2-pyrrolidone-costyrene) hydrogel," Journal of Applied Polymer Science, vol. 82, no. 6, pp. 1404-1409, 2001.

[35] S. Vijayasekaran, T. V. Chirila, Y. Hong et al., "Poly(I-vinyl-2pyrrolidinone) hydrogels as vitreous substitutes: histopathological evaluation in the animal eye," Journal of Biomaterials Science, Polymer Edition, vol. 7, no. 8, pp. 685-696, 1996.

[36] E. Ranucci, G. Spagnoli, L. Sartore et al., "Synthesis and molecular weight characterization of end-functionalized $\mathrm{N}$ vinyl-2-pyrrolidone oligomers," Macromolecular Chemistry and Physics, vol. 196, no. 3, pp. 763-774, 1995.

[37] H. Y. Lee, A. Y. Seol, K. H. Jeong, and Y. J. Kim, "Poly(vinyl pyrrolidone) conjugated lipid system for the hydrophobic drug delivery," Macromolecular Research, vol. 15, no. 6, pp. 547-552, 2007. 


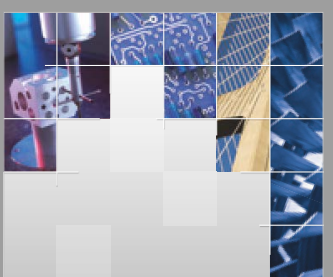

\section{Enfincering}
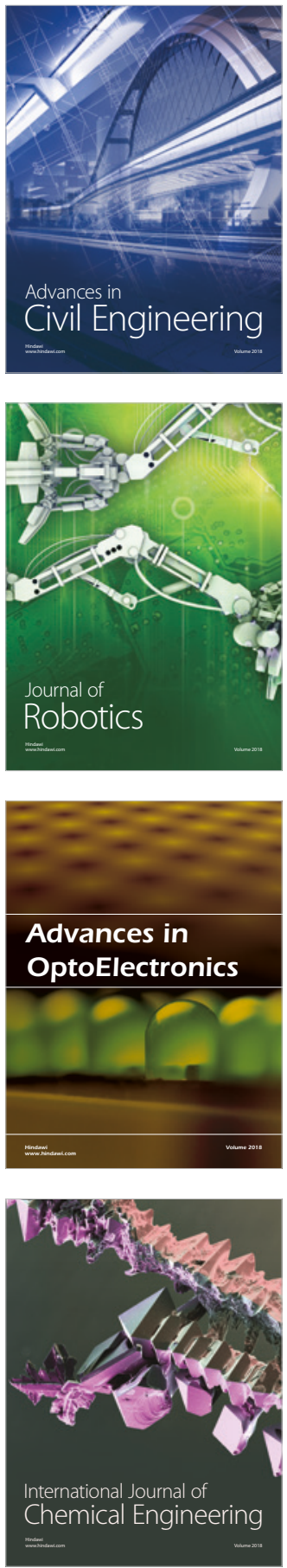

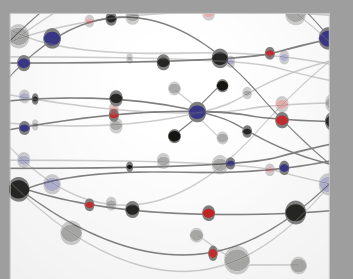

\section{Rotating \\ Machinery}

The Scientific World Journal

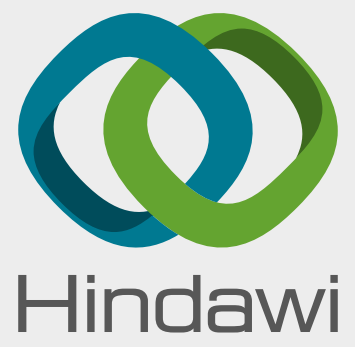

Submit your manuscripts at

www.hindawi.com
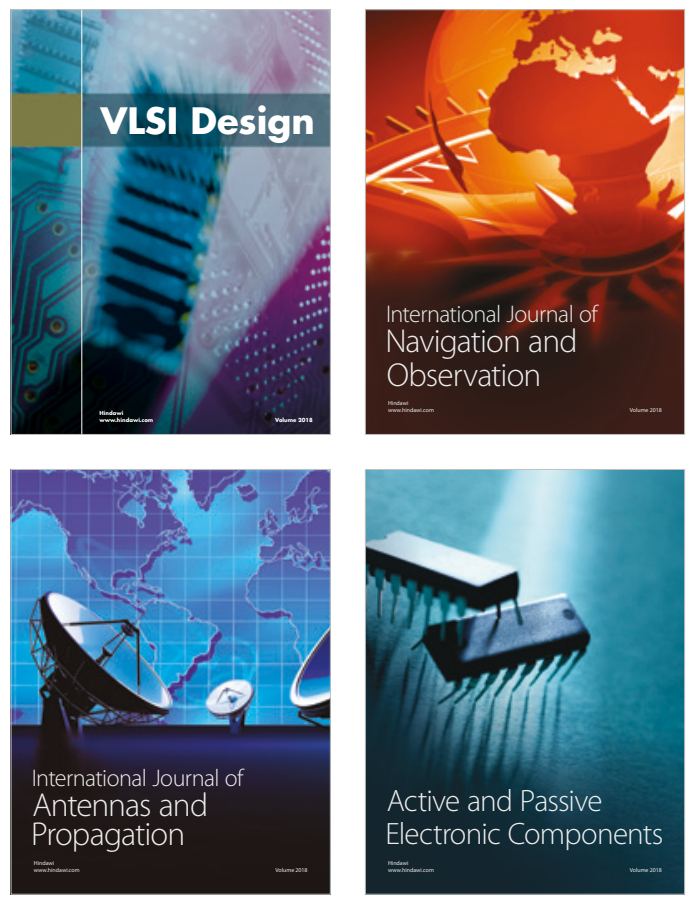
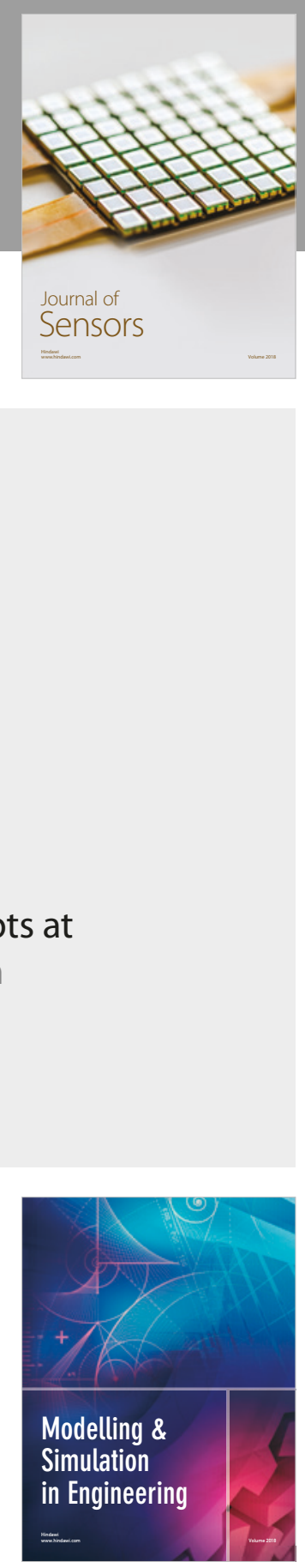

\section{Advances \\ Multimedia}
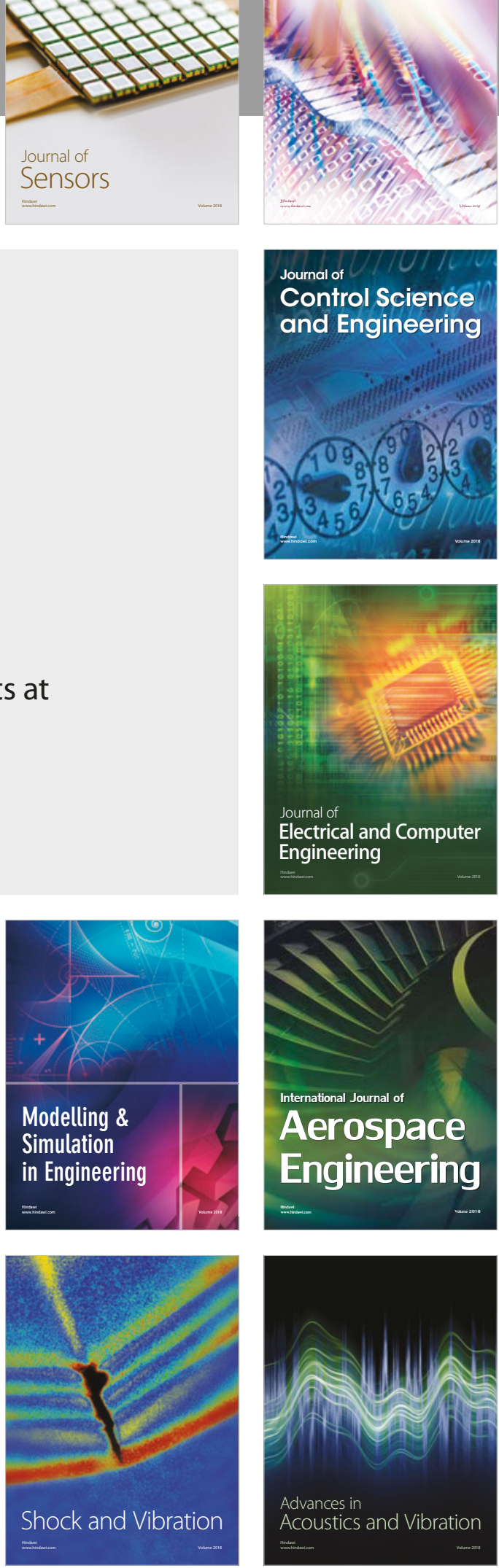